\title{
BMJ Open Quality Patient involvement via videoconference at the morbidity and mortality (M\&M) meeting during COVID-19
}

Britt Jose Myren (D) , J Joanne A de Hullu, ${ }^{1}$ Rosella P M G Hermens, ${ }^{2}$ Jur J Koksma, ${ }^{3}$ Petra L M Zusterzeel ${ }^{1}$
To cite: Myren BJ, de Hullu JA, Hermens RPMG, et al. Patient involvement via videoconference at the morbidity and mortality (M\&M) meeting during COVID-19. BMJ Open Quality 2022;11:e001691. doi:10.1136/ bmjoq-2021-001691

Received 4 0ctober 2021 Accepted 13 January 2022

Check for updates

(C) Author(s) (or their employer(s)) 2022. Re-use permitted under CC BY-NC. No commercial re-use. See rights and permissions. Published by BMJ.

${ }^{1}$ Department of Gynaecology and Obstetrics, Radboudumc, Nijmegen, The Netherlands

${ }^{2}$ Scientific Institute for Quality of Healthcare, Radboudumc,

Nijmegen, The Netherlands

${ }^{3}$ Health Academy, Radboudumc, Nijmegen, The Netherlands

Correspondence to Dr Britt Jose Myren; britt.myren@radboudumc.nl

\section{INTRODUCTION}

The development of online meetings and innovative online patient and public involvement (PPI) increased in the last decade, but the COVID-19 pandemic pushed healthcare delivery towards remote solutions more rapidly. ${ }^{1}$ This may be seen as a logistical, technical as well as a cultural shift. ${ }^{2}$

Due to the COVID-19 pandemic, online programmes and tools have been developed to guide healthcare professionals in setting up video consultations. ${ }^{3}$ Healthcare professionals may benefit from requiring knowledge and skills of digital technology, ethics of online communication and specific communication competences. ${ }^{4}$ Barriers may arise for patients with unfamiliarity with the technology used (often elderly patients), low hearing or vision, or patients who require more emotional support. ${ }^{5}$

COVID-19 also influenced our morbidity and mortality (M\&M) meeting at the department of gynaecology, which we organise with patient participation since $2016 .^{6}$ Involving patients at the M\&M meeting is a form of PPI. During these meetings with the patient (and relatives), adverse events (AEs) are discussed with professionals in order to learn from what happened to eventually improve healthcare. ${ }^{78}$ Due to COVID-19 safety regulations, patients were invited to join the M\&M meeting online instead of in person. The aim of the study is to evaluate the online involvement of patients at M\&M meetings to understand the most important supportive and challenging factors. The outcome of previous research on in person patient involvement at M\&M meetings is used to understand the similarities and differences with online involvement. ${ }^{6}$

\section{METHODS}

Setting

The department of gynaecology organised monthly M\&M meetings that discussed the $\mathrm{AE}$ of one patient. The M\&M meetings in this pilot study followed the same design as in person patient involvement. ${ }^{6}$ The main adjustment was including the safe videoconference tool 'Lifesize'. ${ }^{9}$ This tool required the patient to enter a code and password from home. Patients received a step-by-step plan with instructions to test the tool prior to the meeting. Each meeting was studied prospectively.

\section{Data collection}

Experiences of patients and professionals attending M\&M meetings via Lifesize were evaluated by semistructured interviews and observations (fieldnotes). Professionals who experienced both patient participation in person as well as online were invited for an interview. The interview guide for patients focused on their current experience of an M\&M meeting and their experience with 'Lifesize'; the guide for professionals focused on the similarities and differences between in person and online patient involvement. Informed consent was obtained from each patient prior to participation. Data saturation was reached after five M\&M meetings. Interviews were conducted via telephone, recorded and transcribed by BJM, and lasted between 10:38 $\mathrm{min}$ and 29:26 min. Fieldnotes were written by BJM. Written informed consent and permission were obtained. Data were stored in a folder with a digital key.

In total five M\&M meetings were included in the study. Five patients and eight healthcare professionals participated in the interviews (one consultant, four registrars, one case manager (nurse), one nurse specialist, one coordinator/nurse-researcher). Professionals attended one or several M\&M meetings. Patients' age ranged between 25 and 55 years. The AEs ranged from mild to severe complications, and included haemorrhage after cervical leep excision large loop excision of the transformation zone (LLETZ), 
abdominal abscess, haemorrhage after laparoscopic cystectomy of dermoid cyst, inaccurate diagnosis after biopsy that led to a more invasive procedure than proved necessary after final histology, and leakage of a colorectal anastomosis.

\section{Data analysis}

Atlas.ti V.8.4.20 was used for thematic content analysis of the transcripts of the fieldnotes and the interviews by two researchers (BJM, PLMZ). ${ }^{10}$ After reading all transcripts, open coding was used to descriptively label each phrase or sentence. Similar codes were clustered into subthemes and discussed upon agreement. These subthemes were merged into the five themes that resulted from the evaluation study of in person patient involvement. ${ }^{6}$ Subsequently, if subthemes did not fit in the established thematic framework, they were clustered separately and discussed until consensus was reached (BJM, JAdH, JJK, RPMGH, PLMZ).

\section{RESULTS}

Our findings show that all five themes significant for both patients and professionals attending M\&M meeting with in person patient involvement remained relevant in an online setting: a balanced use of comprehensible language, an established patient-doctor relationship, open communication, personal impact of an $\mathrm{AE}$, and we found comparable medical/technical learning points as well as learning points in the field of communication and collaboration. The relevant themes for online patient involvement were non-verbal communication and experience with a videoconference tool. Table 1 shows an overview of the themes similar to in person M\&M meetings and the themes specific to online patient involvement.

Due to a lack of non-verbal communication in an online setting, professionals experienced that it was difficult to grasp whether patients understood everything and how it impacted them. Additionally, it required extra attention for clear formulations, to speak slowly, to provide regular

Table 1 Themes arising from online patient involvement at morbidity and mortality meetings

\begin{tabular}{lll}
\hline Themes & $\begin{array}{l}\text { Similar to } \\
\text { inperson patient } \\
\text { involvement }^{6}\end{array}$ & $\begin{array}{l}\text { Specific to } \\
\text { online patient } \\
\text { involvement }^{\text {Language }}\end{array}$ \\
\hline $\begin{array}{l}\text { Patient-doctor } \\
\text { relationship }\end{array}$ & $\mathrm{x}$ & \\
$\begin{array}{l}\text { Open communication } \\
\text { Personal impact }\end{array}$ & $\mathrm{x}$ & \\
\hline $\begin{array}{l}\text { Learning } \\
\text { Non-verbal } \\
\text { communication }\end{array}$ & $\mathrm{x}$ & \\
$\begin{array}{l}\text { Experience with } \\
\text { videoconference tool }\end{array}$ & & $\mathrm{x}$ \\
\hline
\end{tabular}

summaries and to invite the patient to respond. Patients experienced the latter as helpful and felt taken seriously. One patient specifically mentioned that a more personal question from a consultant showed that they took an interest in her experience. The question concerned whether the patient would have chosen differently if she would have known back then what she knows now: "I think people should always ask these type of questions. That you should be genuinely interested in what the effect is on a patient when something like that happens" (Patient 1). Patients felt well prepared to use the videoconference tool and knew what to expect from the online meeting. Both professionals and patients mentioned that as a result of COVID-19 they were more used to and/or comfortable with using videoconferencing tools.

Professionals with experience of in person patient attendance would prefer the latter in order to have a better understanding of patients' non-verbal language. Yet all interviewees were satisfied and professionals experienced the patient as a valuable addition. Our learning points of online patient involvement at the M\&M meetings were to have a videoconference system that patients can use easily, that has the option for a second person to $\log$ in during the meeting (companion of the patient), and to facilitate a setting where especially the patient is clearly visible in order to see as much non-verbal communication as possible. In addition, the goal and structure of the M\&M meeting have to be clear for all attendees in order to have an organised meeting and to prevent miscommunication. Table 2 provides a summary of the collected data, clustered in three categories: practical advice, supportive factors and challenging factors of online M\&M meetings.

\section{DISCUSSION}

The online M\&M meeting was implemented rapidly and successfully during COVID-19. Although professionals experienced some limitations, the benefits of patient participation remain the same as for in person involvement. ${ }^{6}$ The experiences of in person patient involvement were positive for both patients and healthcare professionals.

Although comparable learning points resulted from the online meeting, to better understand patients' experiences, professionals may need to develop a skillset that includes, for example, awareness of patients' tone of voice and facial expressions. ${ }^{11-13}$ Less eye contact may make users feel uncomfortable or disconnected by a lack of social presence. ${ }^{14}{ }^{15}$ Yet patients in our research did not express feeling uncomfortable or disconnected. Perhaps, this is related to the preparation, the attendance of familiar faces and the time reserved for patients before, during and after the meeting including emotional support. ${ }^{16}{ }^{17}$ Moreover, it is likely that some patients felt comfortable because they gained experience with videoconference tools for personal or work-related use.

Openness to patient participation and experience with live attendance is important to achieve an inclusive M\&M 
Table 2 Practical advice and supportive and challenging factors

Practical Organise high-quality image and sound in the advice meeting room.

Use a room with two screens: one for the presentation and one for the videoconference.

Organise a user-friendly videoconference tool and provide clear instructions for both professionals and patients.

A partner or family member of the patient can join with the possibility to log in from a different device.

During meeting: welcome the patient first and introduce all attendees.

All attendees are visible.

Frequent summaries during the meeting are helpful.

Actively ask the patient to share their experiences and comments.

Speak slowly with a loud and clear voice.

Do not interrupt speakers.

\begin{tabular}{|c|c|}
\hline \multirow[t]{5}{*}{$\begin{array}{l}\text { Supportive } \\
\text { factors }\end{array}$} & $\begin{array}{l}\text { Prior to the meeting: the patient receives clear } \\
\text { explanation of the structure and goal of the } \\
\text { meeting. }\end{array}$ \\
\hline & $\begin{array}{l}\text { The videoconference tool is tested with the patien } \\
\text { prior to the meeting. }\end{array}$ \\
\hline & $\begin{array}{l}\text { Healthcare professionals have experience with the } \\
\text { conference tool used. }\end{array}$ \\
\hline & $\begin{array}{l}\text { Patients do not have travelling time, which makes } \\
\text { it easier to plan into their daily programme. }\end{array}$ \\
\hline & $\begin{array}{l}\text { Case manager or attending consultant calls } \\
\text { patient afterwards (on the same day). }\end{array}$ \\
\hline \multirow[t]{4}{*}{$\begin{array}{l}\text { Challenging } \\
\text { factors }\end{array}$} & $\begin{array}{l}\text { Some patients may be unfamiliar with } \\
\text { videoconference tools. }\end{array}$ \\
\hline & $\begin{array}{l}\text { Facilities used for Lifesize meetings may not be in } \\
\text { order and functioning properly. }\end{array}$ \\
\hline & Non-verbal language is more difficult to observe. \\
\hline & $\begin{array}{l}\text { There is only one camera facing the meeting } \\
\text { room: the patient sees professionals on a small } \\
\text { scale and it may be difficult to see who is talking. }\end{array}$ \\
\hline
\end{tabular}

meeting, and also to manage changes towards a digital work environment. ${ }^{518}$ Our department will keep inviting patients to M\&M meetings post-COVID-19 to attend either in person or via Lifesize.

Acknowledgements We would like to thank all patients and healthcare professionals for their time to participate in the research.

Contributors BJM: conceptualisation, methodology, software, formal analysis, investigation, data curation, writing - original draft, writing - review and editing, visualisation, project administration. JAdH: conceptualisation, formal analysis, validation, investigation, resources, writing - review and editing. JJK: conceptualisation, methodology, validation, formal analysis, data curation, writing - review and editing. RPMGH: conceptualisation, validation, methodology, investigation, formal analysis, resources, writing - review and editing. PLMZ: conceptualisation, validation, investigation, formal analysis, resources, data curation, writing - review and editing, supervision.
Funding The authors have not declared a specific grant for this research from any funding agency in the public, commercial or not-for-profit sectors.

Competing interests None declared.

Patient and public involvement Patients and/or the public were involved in the design, or conduct, or reporting, or dissemination plans of this research. Refer to the Methods section for further details.

Patient consent for publication Not required.

Ethics approval This study involves human participants. The study (case 20184713) was waived by the Ethical Review Board Arnhem-Nijmegen of the hospital Radboudumc (CMO Light). Participants gave informed consent to participate in the study before taking part.

Provenance and peer review Not commissioned; externally peer reviewed.

Open access This is an open access article distributed in accordance with the Creative Commons Attribution Non Commercial (CC BY-NC 4.0) license, which permits others to distribute, remix, adapt, build upon this work non-commercially, and license their derivative works on different terms, provided the original work is properly cited, appropriate credit is given, any changes made indicated, and the use is non-commercial. See: http://creativecommons.org/licenses/by-nc/4.0/.

\section{ORCID iD}

Britt Jose Myren http://orcid.org/0000-0002-6265-7468

\section{REFERENCES}

1 Brighton LJ, Pask S, Benalia $\mathrm{H}$, et al. Taking patient and public involvement online: qualitative evaluation of an online forum for palliative care and rehabilitation research. Res Involv Engagem 2018;4:14.

2 Wherton J, Shaw S, Papoutsi C, et al. Guidance on the introduction and use of video consultations during COVID-19: important lessons from qualitative research. BMJ Leader 2020;4:leader2020-000262:120-3.

3 British Journal of general practice (BJGP) life. https://bjgplife.com/ video-consultations-guide-for-practice/. Available: https://bjgplife. com/video-consultations-guide-for-practice/ [Accessed 18 Feb 2021].

4 Konttila J, Siira H, Kyngäs H, et al. Healthcare professionals' competence in digitalisation: a systematic review. J Clin Nurs 2019;28:745-61.

5 Almathami HKY, Win KT, Vlahu-Gjorgievska E. Barriers and facilitators that influence telemedicine-based, real-time, online consultation at patients' homes: systematic literature review. J Med Internet Res 2020;22:e16407.

6 Myren BJ, Hermens RPMG, Koksma JJ, et al. Openness to new perspectives created by patient participation at the morbidity and mortality meeting. Patient Educ Couns 2021;104:343-51.

7 Vreugdenburg TD, Forel D, Marlow N, et al. Morbidity and mortality meetings: gold, silver or bronze? ANZ J Surg 2018;88:966-74.

8 Verhagen MJ, de Vos MS, Hamming JF. Taking morbidity and mortality conferences to a next level: the resilience engineering concept. Ann Surg 2020;272:678-83.

9 Lifesize. Available: https://www.lifesize.com/en/

10 Sundler AJ, Lindberg E, Nilsson C, et al. Qualitative thematic analysis based on descriptive phenomenology. Nurs Open 2019;6:733-9.

11 Liu X, Chen M, Li J, et al. How to manage diversity and enhance team performance: evidence from online doctor teams in China. Int $J$ Environ Res Public Health 2019;17. doi:10.3390/ijerph17010048. [Epub ahead of print: 1912 2019].

12 Jiménez-Rodríguez D, Santillán García A, Montoro Robles J, et al. Increase in video consultations during the COVID-19 pandemic: healthcare professionals' perceptions about their implementation and adequate management. Int J Environ Res Public Health 2020;17. doi:10.3390/ijerph17145112. [Epub ahead of print: 1507 2020].

13 Williams A, Larocca R, Chang T, et al. Web-based depression screening and psychiatric consultation for college students: a feasibility and acceptability study. Int J Telemed Appl 2014;2014:580786.

14 Ehlers DK, Huberty JL, de Vreede G-J. Can an evidence-based book club intervention delivered via a tablet computer improve physical activity in middle-aged women? Telemed J E Health 2015;21:125-31.

15 Eslami Jahromi M, Ahmadian L. Evaluating satisfaction of patients with stutter regarding the tele-speech therapy method and infrastructure. Int J Med Inform 2018;115:128-33. 
16 Demiris G, Speedie SM, Finkelstein S. Change of patients' perceptions of TeleHomeCare. Telemed J E Health 2001;7:241-8.

17 Burkow TM, Vognild LK, Johnsen E, et al. Comprehensive pulmonary rehabilitation in home-based online groups: a mixed method pilot study in COPD. BMC Res Notes 2015;8:766.
18 Keyworth C, Hart J, Armitage CJ, et al. What maximizes the effectiveness and implementation of technology-based interventions to support healthcare professional practice? A systematic literature review. BMC Med Inform Decis Mak 2018;18:93. 